\section{Federation University ResearchOnline}

https://researchonline.federation.edu.au

Copyright Notice

This is the peer-reviewed version of the following article:

Abu-Siada, A., Hmood, S., \& Islam, S. (2013). A new fuzzy logic approach for consistent interpretation of dissolved gas-in-oil analysis. IEEE Transactions on Dielectrics and Electrical Insulation, 20(6), 2343-2349.

Available online: https://doi.org/10.1109/TDEl.2013.6678888

Copyright ( 2013 IEEE. Personal use of this material is permitted. Permission from IEEE must be obtained for all other uses, in any current or future media, including reprinting/republishing this material for advertising or promotional purposes, creating new collective works, for resale or redistribution to servers or lists, or reuse of any copyrighted component of this work in other works. 
Copyright (C) 2013 IEEE. Personal use of this material is permitted. Permission from IEEE must be obtained for all other uses, in any current or future media, including

reprinting/republishing this material for advertising or promotional purposes, creating new collective works, for resale or redistribution to servers or lists, or reuse of any copyrighted component of this work in other works. 


\title{
A New Fuzzy Logic Approach for Consistent Interpretation of Dissolved Gas-in-Oil Analysis
}

\author{
A. Abu-Siada, S. Hmood and S. Islam \\ Curtin University, Perth \\ WA6102, Australia
}

\begin{abstract}
Dissolved gas analysis (DGA) of transformer oil is one of the most effective power transformer condition monitoring tools. There are many interpretation techniques for DGA results however all these techniques rely on personnel experience more than analytical formulation. As a result, various interpretation techniques do not necessarily lead to the same conclusion for the same oil sample. Furthermore, significant number of DGA results fall outside the proposed codes of the current based-ratio interpretation techniques and cannot be diagnosed by these methods. Moreover, ratio methods fail to diagnose multiple fault conditions due to the mixing up of produced gases. To overcome these limitations, this paper introduces a new fuzzy logic approach to reduce dependency on expert personnel and to aid in standardizing DGA interpretation techniques. The approach relies on incorporating all existing DGA interpretation techniques into one expert model. DGA results of 2000 oil samples that were collected from different transformers of different rating and different life span are used to establish the model. Traditional DGA interpretation techniques are used to analyze the collected DGA results to evaluate the consistency and accuracy of each interpretation technique. Results of this analysis were then used to develop the proposed fuzzy logic model.
\end{abstract}

Index Terms — Transformer Diagnosis, Condition monitoring, DGA, Fuzzy logic.

\section{$1 \quad$ INTRODUCTION}

POWER transformers represent a critical link in any transmission or distribution network. To improve the reliability of the equipment and to avoid any catastrophic failure, effective monitoring and diagnostic techniques must be adopted. Transformer dielectric oil and paper insulation are considered as key sources to detect incipient and fast developing faults, insulation trending and generally reflects the health condition of the transformer [1]. There are several of chemical and electrical diagnostic techniques currently used by various utilities to examine the health condition of power transformers [2]. Among of these methods, dissolved gas in oil analysis (DGA) is widely used to detect power transformer incipient faults. Due to electrical and thermal stresses that inservice transformer exhibits, oil and paper decomposition occurs [3]. Gases produced due to oil decomposition are hydrogen $\left(\mathrm{H}_{2}\right)$, methane $\left(\mathrm{CH}_{4}\right)$, acetylene $\left(\mathrm{C}_{2} \mathrm{H}_{2}\right)$, ethylene $\left(\mathrm{C}_{2} \mathrm{H}_{4}\right)$ and ethane $\left(\mathrm{C}_{2} \mathrm{H}_{6}\right)$. On the other hand paper decomposition produces carbon monoxide $(\mathrm{CO})$ and carbon dioxide $\left(\mathrm{CO}_{2}\right)$ [4]. Various internal faults within a power transformer evolve particular amount of characteristic gases that can be used to determine the type of fault. However, the analysis is not always straight forward as there may be more than one fault present at the same time. Partial discharge activity produces $\mathrm{H}_{2}$ and $\mathrm{CH}_{4}$ while arcing generates all gases including traceable amount of $\mathrm{C}_{2} \mathrm{H}_{2}$ [3]. DGA can be used to determine the amount and type of gases in transformer oil and hence aiding in determining the transformer failure rank $[5,6]$. There are many DGA interpretation techniques such as key gas method [7, 8], Roger ratio method [9, 10] and Duval triangle method [11] that have been reported in the literatures.
All of these techniques rely on personnel experience more than mathematical formulation and they do not necessarily lead to the same conclusion for the same oil sample. Precise DGA interpretation is yet a challenge in the power transformer condition monitoring research area and there is no globally accepted technique for DGA interpretation.

Availability of DGA data history has recently motivated researchers to develop a standard approaches for DGA interpretation based on mathematical and artificial intelligent (AI) techniques [12-16]. The application of AI in the interpretation of DGA results are mainly to overcome the drawbacks arise from the application of ratio methods that include failure to identify fault types in case of multiple fault conditions and the invalid code that some DGA data may result in.

A recent study [17] shows that various DGA interpretation techniques are not consistent and they may lead to different interpretation for the same oil sample. To verify this finding, consistency and accuracy analyses are performed on 2000 DGA results of transformer oil samples that were collected from various transformers of different rating, life span and operating conditions. Results of consistency and accuracy analyses are then used to develop a fuzzy logic model that incorporates the key features of several well established DGA interpretation techniques such as Roger, Doerenburg, IEC ratio methods along with key gas and Duval triangle methods. The model provides one result based on all of these techniques to assure a reliable and consistent decision on the health condition of the transformer oil. The model however, is built to enable the user to observe the output of each individual method as will be elaborated in section 3 . 


\section{DGA INTERPRETATION TECHNIQUES}

There are many DGA interpretation techniques currently used by various utilities. Among these techniques the Roger, Doerenburg, IEC, key gas and Duval triangle are the most popular and widely used methods. These methods are well established in the literature and they are briefly elaborated below to highlight the limitation of each technique.

Roger's ratio method which is based on earlier work by Doerenburg, uses four-key gas ratios [18]. On the other hand, the IEC ratio method uses three-key gas ratios[19]. Ratio methods are only valid if a significant amount of the gas used in the ratio is present otherwise the method will not be able to identify the type of fault and will lead to invalid code. Therefore, ratio methods can be used to identify the type of fault more than detecting it.

The key gas method is set forth in IEEE standard (C57.1041991) that was revised in 2008 [7, 18] for transformer oil DGA interpretation. This method uses combination of individual gases and total combustible gas concentration (TCGC) to classify risks within a transformer. However, this guide is not widely accepted as an effective tool to evaluate the health condition of in-oil immersed transformers as it is considered very conservative and a transformer may operate safely even though its DGA analysis indicates condition 4 (imminent risk) as far as gas evolution rate is not constantly increasing [3].

Duval and De Pablo mentioned that good number of DGA results fall outside ratio-based interpretation techniques and cannot be diagnosed using these methods. Duval proposed a triangle for transformer fault diagnosis based on DGA results [11]. However as Duval triangle does not encompass an area for normal DGA results, this method can only be used to identify the fault type in case of faulty transformer and therefore, no indication of incipient fault can be obtained [19].

\section{FUZZY LOGIC MODELS}

In this section, fuzzy logic models are developed to aid in standardizing the overall decision of various DGA interpretation techniques. Each fuzzy logic model is developed in accordance to fuzzy inference flow chart shown in Fig. 1. Input variables to the model are the concentration of the 7-key gases in parts per million (ppm). The output of each model is divided into 5 sets of membership functions comprising all fault conditions that operating transformers may exhibit along with a membership function for normal condition (F5) as summarized in Table 1 [7, 12, 19]. A membership function (F6) is added to represent the "out of code" condition that ratio methods may lead to for some DGA samples. The output membership functions for all models are shown in Fig. 2.

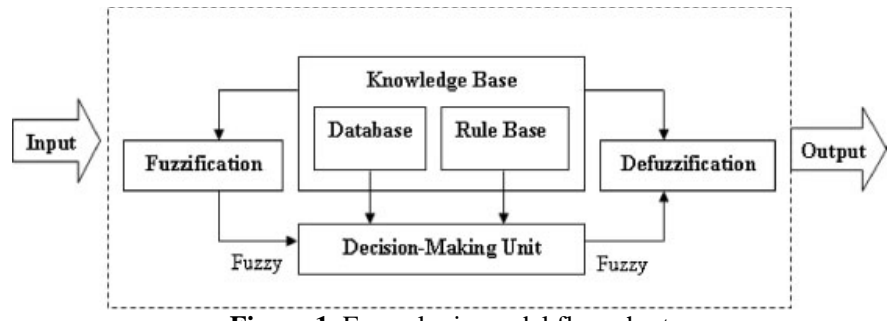

Figure 1. Fuzzy logic model flow chart
Table 1. Fault types

\begin{tabular}{|c|c|c|c|c|}
\hline$\frac{3}{2}$ & $\begin{array}{c}\text { F1 } \\
\text { Thermal fault } \\
\text { (Cellulose) }\end{array}$ & $\begin{array}{c}\mathrm{F} 2 \\
\text { Thermal fault } \\
\text { (Oil) }\end{array}$ & $\begin{array}{c}\text { F3 } \\
\text { Electrical fault } \\
\text { (Corona) }\end{array}$ & $\begin{array}{c}\text { F4 } \\
\text { Electrical fault } \\
\text { (Arcing) }\end{array}$ \\
\hline 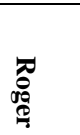 & $\begin{array}{l}\text {-Thermal fault } \\
<150^{\circ} \mathrm{C} \text {. } \\
\text {-Thermal fault } \\
150-300^{\circ} \mathrm{C}\end{array}$ & $\begin{array}{c}\text {-Thermal fault } \\
300-700^{\circ} \mathrm{C} \\
- \text { Thermal fault } \\
>700^{\circ} \mathrm{C}\end{array}$ & $\begin{array}{l}\text {-Low energy } \\
\text { electrical } \\
\text { discharge }\end{array}$ & $\begin{array}{c}\text { - High energy } \\
\text { electrical } \\
\text { discharge }\end{array}$ \\
\hline 정 & $\begin{array}{l}\text {-Thermal fault } \\
<150^{\circ} \mathrm{C} \text {. } \\
\text {-Thermal fault } \\
150-300^{\circ} \mathrm{C}\end{array}$ & $\begin{array}{l}\text {-Thermal fault } \\
300-700^{\circ} \mathrm{C} \\
\text {-Thermal fault } \\
>700^{\circ} \mathrm{C}\end{array}$ & $\begin{array}{l}\text { - Low energy } \\
\text { electrical } \\
\text { discharge }\end{array}$ & $\begin{array}{c}\text { - High energy } \\
\text { electrical } \\
\text { discharge }\end{array}$ \\
\hline 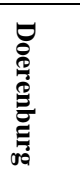 & $\begin{array}{c}\text {-Thermal } \\
\text { decomposition }\end{array}$ & $\begin{array}{c}\text {-Thermal } \\
\text { decomposition }\end{array}$ & $\begin{array}{l}\text { - Low energy } \\
\text { electrical } \\
\text { discharge }\end{array}$ & $\begin{array}{c}\text { - High energy } \\
\text { electrical } \\
\text { discharge }\end{array}$ \\
\hline 氖 & $\begin{array}{l}\text {-Thermal fault } \\
\quad<300^{\circ} \mathrm{C}\end{array}$ & $\begin{array}{c}\text {-Thermal fault } \\
300-700^{\circ} \mathrm{C} \\
- \text { Thermal fault } \\
>700^{\circ} \mathrm{C}\end{array}$ & $\begin{array}{l}\text { - Low energy } \\
\text { electrical } \\
\text { discharge }\end{array}$ & $\begin{array}{l}\text { - High energy } \\
\text { electrical } \\
\text { discharge }\end{array}$ \\
\hline 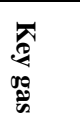 & $\begin{array}{l}\text {-Over heated } \\
\text { cellulose }\end{array}$ & -Over heated oil & $\begin{array}{l}\text { - Low energy } \\
\text { electrical } \\
\text { discharge }\end{array}$ & $\begin{array}{c}\text { - High energy } \\
\text { electrical } \\
\text { discharge }\end{array}$ \\
\hline . & $\mathrm{CO}$ & $\mathrm{C}_{2} \mathrm{H}_{4}$ & $\mathrm{H}_{2}$ & $\mathrm{C}_{2} \mathrm{H}_{2}$ \\
\hline
\end{tabular}

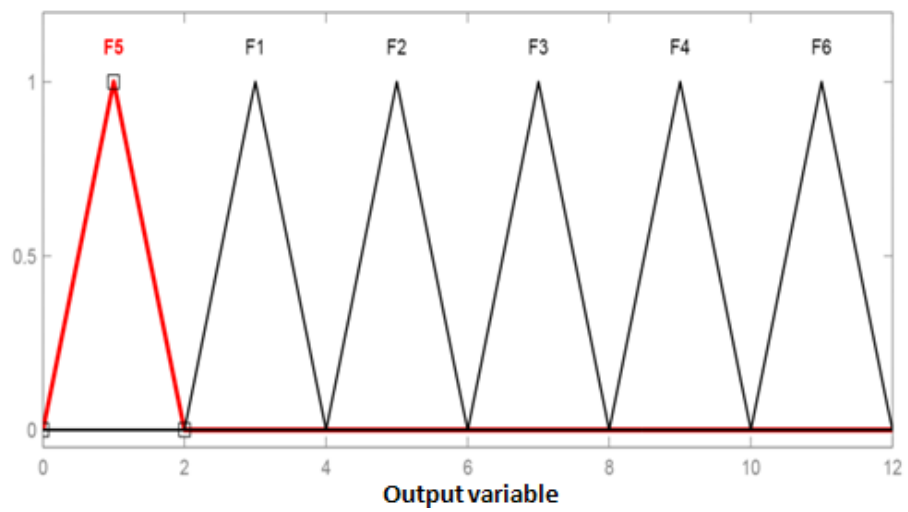

Figure 2. Fuzzy logic models output membership functions

Table 1 is established based on the fact that gases are formed inside an oil-filled transformer at particular range of temperatures as specified in the combustible gas generation temperature [19] and Hastead's thermal charts [7]. Cellulosic thermal decomposition produces $\mathrm{CO}$ and $\mathrm{CO}_{2}$ at lower temperature than oil decomposition [7] and traceable amount of $\mathrm{CO}$ and $\mathrm{CO}_{2}$ can be found at normal operating condition. For a confirmed decision on paper degradation condition, the ratio $\mathrm{CO}_{2} / \mathrm{CO}$ is used [7]. However, this ratio is not a reliable indicator for paper health condition and other tests such as furan analysis or if possible, degree of polymerisation should be conducted to provide an affirmed decision on the paper condition $[17,20]$. Oil thermal decomposition starts at higher temperature and at about $350^{\circ} \mathrm{C}$ production of $\mathrm{C}_{2} \mathrm{H}_{4}$ begins. At about $450{ }^{\circ} \mathrm{C}, \mathrm{H}_{2}$ production exceeds all other gases causing 
low-intensity discharges such as partial discharge and very low level intermittent arcing [7]. At about $700{ }^{\circ} \mathrm{C}$, more $\mathrm{C}_{2} \mathrm{H}_{2}$ is produced causing high intensity arcing or continuing discharge proportion [7].

Each fuzzy model is built using the graphical user interface tool provided by MATLAB where each input is fuzzified into various sets (normal to significant) of membership functions. Centre-of-gravity which is widely used in fuzzy models, was used for defuzzification method where the desired output $z_{0}$ is calculated as [21] :

$$
z_{0}=\frac{\int z \cdot \mu_{c}(z) d z}{\int \mu_{c}(z) d z}
$$

where $\mu_{c}(z)$ is the membership function of the output.

A set of fuzzy logic rules in the form of (IF-AND-THEN) statements relating the input to the output variables was developed based on transformer's diagnoses and test data interpretation techniques $[22,23]$ as elaborated below.

\section{A. Key Gas Fuzzy Logic Model}

Membership functions for the seven input gases are established based on the amount of gases present in oil sample. Set of fuzzy rules are developed as shown in Fig. 3. The model is tested with inputs, $\mathrm{H}_{2}(80 \mathrm{ppm}), \mathrm{CH}_{4}(100 \mathrm{ppm})$, $\mathrm{C}_{2} \mathrm{H}_{6}$ (60 ppm), $\mathrm{C}_{2} \mathrm{H}_{4}$ (45 ppm), $\mathrm{C}_{2} \mathrm{H}_{2}$ (15 ppm), CO (250 ppm), $\mathrm{CO}_{2}(1500 \mathrm{ppm})$ and total dissolved combustible gas (TDCG) (550 ppm) as detected in a transformer oil sample using DGA. As the amount of all key gases and TDCG are within normal condition according to the IEEE standard, the model output is 1 which is corresponding to F5 (normal condition).

Figure 3. Key gas Fuzzy rules

\section{B. Duval Triangle Fuzzy Logic Model}

The set of fuzzy rules relates the inputs to the output variable developed for this method is shown in Fig. 4. The model is tested with inputs, $\mathrm{CH}_{4} /\left(\mathrm{C}_{2} \mathrm{H}_{2}+\mathrm{C}_{2} \mathrm{H}_{4}+\mathrm{CH}_{4}\right)(8 \%)$, $\mathrm{C}_{2} \mathrm{H}_{4} /\left(\mathrm{C}_{2} \mathrm{H}_{2}+\mathrm{C}_{2} \mathrm{H}_{4}+\mathrm{CH}_{4}(15 \%)\right.$ and $\mathrm{C}_{2} \mathrm{H}_{2} /\left(\mathrm{C}_{2} \mathrm{H}_{2}+\mathrm{C}_{2} \mathrm{H}_{4}+\mathrm{CH}_{4}\right)$ $(7.5 \%)$ as detected in a transformer oil sample using DGA. The fuzzy logic model provides 7.04 which is corresponding to F3 (partial discharge fault).

Figure 4. Duval fuzzy rules

\section{IEC Ratio Fuzzy Logic Model}

The developed set of fuzzy rules relates the input and the output variables for IEC ratio method is shown in Fig. 5. The model is tested with inputs, $\mathrm{C}_{2} \mathrm{H}_{2} / \mathrm{C}_{2} \mathrm{H}_{4}(0.15), \mathrm{CH}_{4} / \mathrm{H}_{2}$ (2.5) and $\mathrm{C}_{2} \mathrm{H}_{4} / \mathrm{C}_{2} \mathrm{H}_{6}(5)$. The fuzzy logic model numerical output is 9.38, which is corresponding to F4 (arcing fault).

Figure 5. IEC fuzzy rules

\section{Roger's Ratio Fuzzy Logic Model}

The developed set of fuzzy rules relates the inputs to the output variable for this method is shown in Fig. 6. The model is tested with all input ratios equal to 2.5 that result in a numerical output of 11 which is corresponding to F6 (out of 
code). This reveals that DGA results of this oil sample cannot be diagnosed using Roger's ratio method.

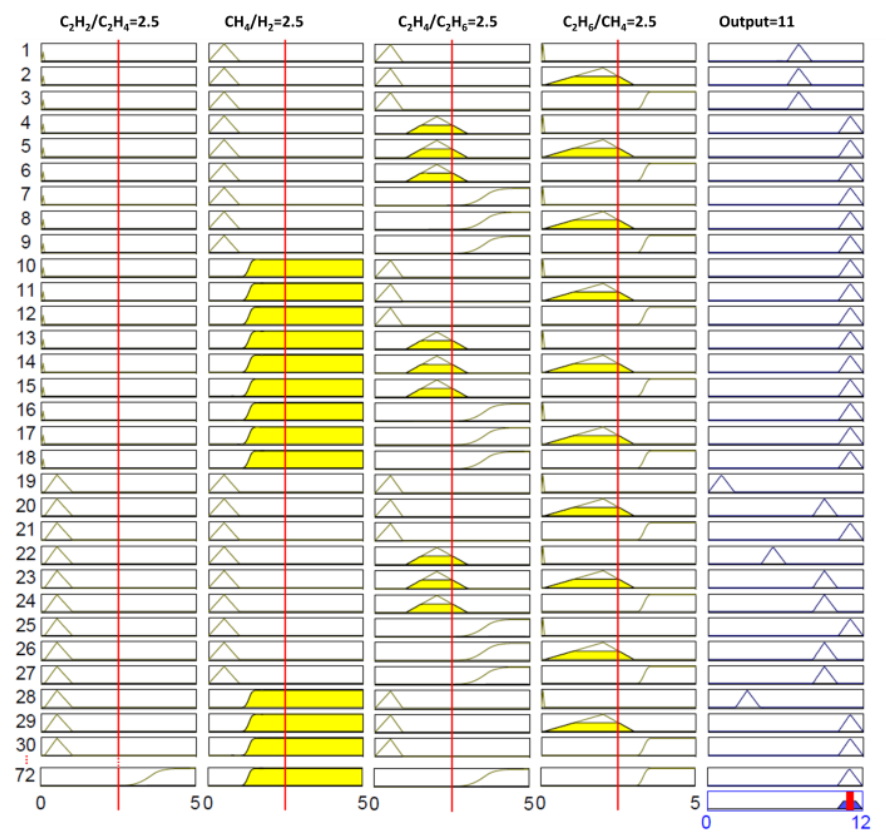

Figure 6. Roger ratio fuzzy rules

\section{E. Doerenburg Fuzzy Logic Model}

Set of fuzzy rules relates the input and the output variables are developed based on Doerenburg interpretation code (Table 2 [18]) as shown in Fig. 7. The model is tested with inputs, $\mathrm{CH}_{4} / \mathrm{H}_{2} \quad(0.5), \quad \mathrm{C}_{2} \mathrm{H}_{2} / \mathrm{C}_{2} \mathrm{H}_{4} \quad(1.5), \quad \mathrm{C}_{2} \mathrm{H}_{2} / \mathrm{CH}_{4} \quad(0.5)$ and $\mathrm{C}_{2} \mathrm{H}_{6} / \mathrm{C}_{2} \mathrm{H}_{2}$ (0.25). The fuzzy logic model output is 9 which is corresponding to $\mathrm{F} 4$ (arcing fault).

Table 2. Doerenburg ratio and diagnosis [18]

\begin{tabular}{|c|c|c|c|c|c|c|c|c|}
\hline $\mathrm{Fal}$ & \multicolumn{2}{|c|}{$\mathrm{R}_{1}=\mathrm{CH}_{4} / \mathrm{H}_{2}$} & \multicolumn{2}{|c|}{$\mathrm{R}_{2}=\mathrm{C}_{2} \mathrm{H}_{2} / \mathrm{C}_{2} \mathrm{H}_{4}$} & \multicolumn{2}{|c|}{$\mathrm{R}_{3}=\mathrm{C}_{2} \mathrm{H}_{2} / \mathrm{CH}_{4}$} & \multicolumn{2}{|c|}{$\mathrm{R}_{4}=\mathrm{C}_{2} \mathrm{H}_{6} / \mathrm{C}_{2} \mathrm{H}_{2}$} \\
\hline The & & $\mathrm{P}>1$ & $\mathrm{R}_{2}<0.75$ & $\mathrm{R}_{2}<1$ & & $\mathrm{R}_{3}<0.1$ & & \\
\hline & & & Not & . & & & & \\
\hline & $\mathrm{R}_{1}$ & $\mathrm{R}_{1}<$ & $2>0.75$ & $\mathrm{R}_{2}>1.0$ & .3 & $\mathrm{R}_{3}>0.1$ & 0.4 & $\mathrm{R}_{4}<0.2$ \\
\hline
\end{tabular}
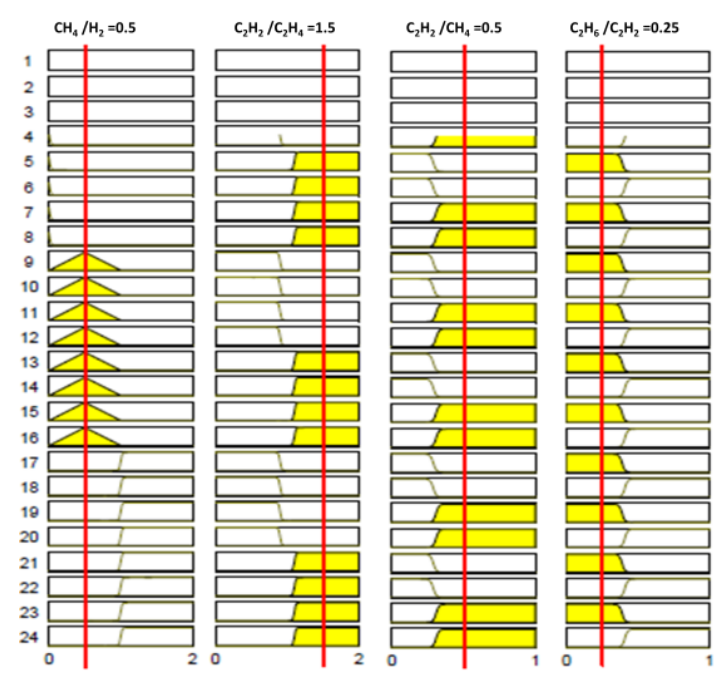

Figure 7. Doerenburg fuzzy rules

\section{CONSISTENC and ACCURCY ANALYSIS}

DGA results of 2000 oil samples with pre-known fault type that were collected from different transformers of different ratings and different operating life span (2 years to 40 years) are used in this analysis. Diagnostic methods were grouped according to fault types as shown in Table 1 [12]. All the 2000 DGA data were analysed using the developed 5 individual fuzzy logic models (key gas, Duval, IEC, Roger and Doerenburg) against the fault types shown in Table 1.

The consistency $(C)$ and accuracy $(A)$ of each method is calculated based on its successful prediction $(P)$ in identifying various faults as below [12].

$$
\begin{aligned}
& S_{f n}=\frac{P_{f n}}{\text { Numberofcasesof } f_{n}} \times 100 \\
& C=\frac{\sum_{1}^{f_{n}} S_{f n}}{\text { Number of fault types }} \\
& A=\frac{T_{s p}}{T_{t c}} \times 100
\end{aligned}
$$

where $S_{f n}$ is the percentage of successful prediction of a particular fault type $f_{n}, T_{s p}$ is the total successful prediction cases and $T_{t c}$ is the total number of cases.

Among the 2000 oil samples, 487 samples were found to be faulty and they are used to assess the consistency and accuracy of each method to identify various types of faults. Table 3 shows the success rate of each method in identifying different types of faults from which it can be concluded that Duval triangle is the most consistent method in identifying thermal

\begin{tabular}{|c|c|c|c|c|c|}
\hline Method & $\begin{array}{l}\text { Fault } \\
\text { code }\end{array}$ & $\begin{array}{c}\text { Prediction } \\
\text { number }\end{array}$ & $\begin{array}{l}\text { Successful } \\
\text { prediction }\end{array}$ & $\begin{array}{c}\text { Successfu } \\
\text { \%age }\end{array}$ & $\begin{array}{l}\text { Consistency } \\
\text { (C) }\end{array}$ \\
\hline \multirow{4}{*}{$\begin{array}{l}\pi \\
0 \\
00 \\
0 \\
9\end{array}$} & F1 & 33 & 9 & $27.3 \%$ & \multirow{4}{*}{$50.4 \%$} \\
\hline & F2 & 44 & 28 & $63.6 \%$ & \\
\hline & F3 & 107 & 65 & $60.7 \%$ & \\
\hline & $\mathrm{F} 4$ & 4 & 2 & $50 \%$ & \\
\hline \multirow{4}{*}{ 莒 } & F1 & 62 & 10 & $16 \%$ & \multirow{4}{*}{$53.3 \%$} \\
\hline & F2 & 31 & 20 & $64.5 \%$ & \\
\hline & F3 & 135 & 100 & $74 \%$ & \\
\hline & F4 & 17 & 10 & $58.8 \%$ & \\
\hline \multirow{4}{*}{ 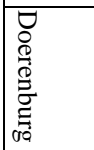 } & F1 & 65 & 17 & $26.2 \%$ & \multirow{4}{*}{$56.2 \%$} \\
\hline & F2 & 188 & 159 & $84.6 \%$ & \\
\hline & F3 & 169 & 112 & $66.3 \%$ & \\
\hline & F4 & 65 & 31 & $47.7 \%$ & \\
\hline \multirow{4}{*}{ 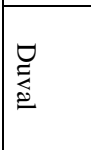 } & F1 & 93 & 60 & $64.5 \%$ & \multirow{4}{*}{$86.2 \%$} \\
\hline & $\mathrm{F} 2$ & 142 & 138 & $97.2 \%$ & \\
\hline & F3 & 169 & 169 & $100 \%$ & \\
\hline & F4 & 83 & 69 & $83.1 \%$ & \\
\hline \multirow{4}{*}{ 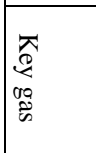 } & F1 & 57 & 38 & $66.7 \%$ & \multirow{4}{*}{$80.7 \%$} \\
\hline & $\mathrm{F} 2$ & 351 & 209 & $59.5 \%$ & \\
\hline & F3 & 56 & 56 & $100 \%$ & \\
\hline & F4 & 23 & 22 & $96.7 \%$ & \\
\hline
\end{tabular}
faults (F1 and F2). On the other hand, key gas is the most consistent method in identifying electrical faults ( $\mathrm{F} 3$ and $\mathrm{F} 4$ ).

The overall consistency for each method is calculated as the average of the successful prediction rates of the four fault types. As shown in Table 3, Duval triangle method is the most consistent method and Roger's ratio is the least consistent method in identifying various faults. This is attributed to the fact that ratio methods may lead to out-of-code ratios in some 
cases. In terms of accuracy, Table 4 shows that Duval triangle is the most accurate technique followed by key gas and Doerenburg methods while IEC and Roger ratio are the least accurate methods. Results in Tables 3 and 4 are shown in Fig. 8.

Table 4. Accuracy analysis of Various DGA interpretation methods

\begin{tabular}{|l|l|l|l|l|l|}
\hline Method & Roger & IEC & Doern. & Duval & Key Gas \\
\hline Total case & 487 & 487 & 487 & 487 & 487 \\
\hline No prediction & 299 & 242 & 0 & 0 & 0 \\
\hline Prediction Number & 188 & 245 & 487 & 487 & 487 \\
\hline $\begin{array}{l}\text { Successful prediction } \\
\text { cases }\left(T_{s p}\right)\end{array}$ & 107 & 140 & 319 & 436 & 325 \\
\hline Accuracy predicted $(A)$ & $22 \%$ & $28.7 \%$ & $65.5 \%$ & $89.5 \%$ & $66.7 \%$ \\
\hline
\end{tabular}

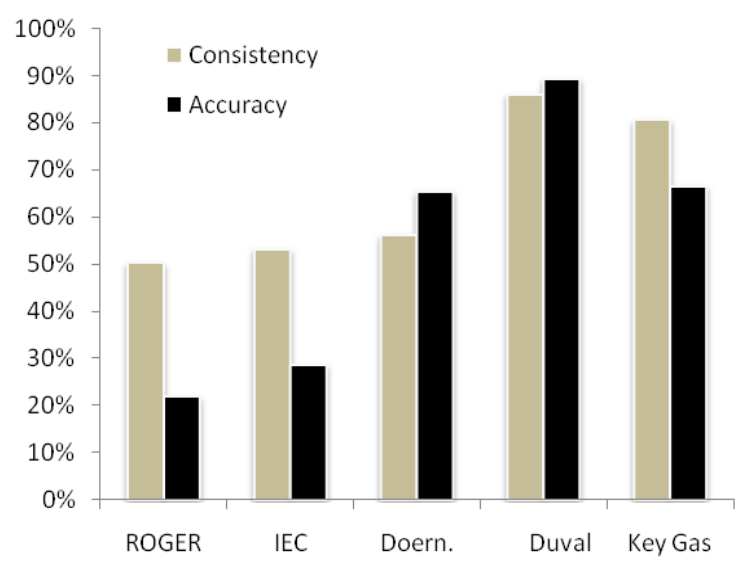

Figure 8. Consistency and Accuracy comparison of all methods

The above results prove that DGA interpretation is not an exact science and there is no $100 \%$ consistency among the existing DGA interpretation techniques [18, 24]. To overcome this drawback, a fuzzy logic model based on the integration of all aforementioned methods is proposed and discussed in the following section.

\section{$5 \quad$ Proposed Approach}

The new approach is based on the incorporation of different DGA interpretation techniques into one prototype software model as shown in the flow chart of Fig. 9. In Fig. 9, key gas method is firstly used to determine the health condition of the transformer oil sample based on its DGA results. If the concentration of individual key gases along with the TDCG is within normal condition according to the IEEE standard, the model reports normal condition and no further analysis will be performed. However, if the key gas method results in abnormal condition, the DGA results will be further analysed using Duval triangle and ratio methods (IEC, Roger and Doerenburg) to accurately identify the fault type. The overall decision $(D)$ is calculated based on the accuracy level of each method according to the following equation:

$$
D=\frac{\sum_{i=1}^{i=5} A_{i} D_{i}}{\sum_{i=1}^{i=5} A_{i}}
$$

where $D_{i}$ is the decision of each individual method weighted by its accuracy level $A_{i}$ calculated in section 4 (Table 3 ).

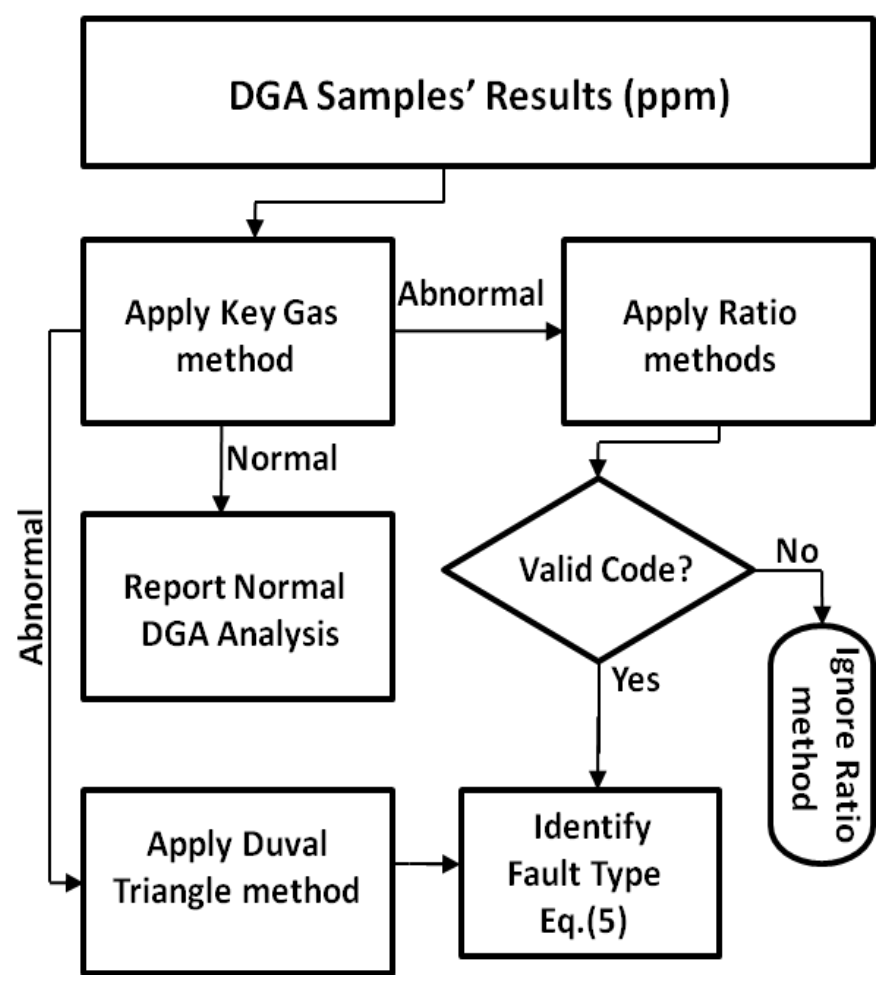

Figure 9. Flow chart of the proposed approach

In case any of the ratio methods provides a ratio that does not fit into the diagnostic codes, the decision value corresponding to this method is set to zero. Normal condition is only specified by key gas method while in case of faulty condition, the fault is specified by all methods according to (5). To implement the flow chart in Fig. 9, the individual fuzzy logic models for various DGA interpretation techniques are integrated in one fuzzy model as shown in Fig. 10.

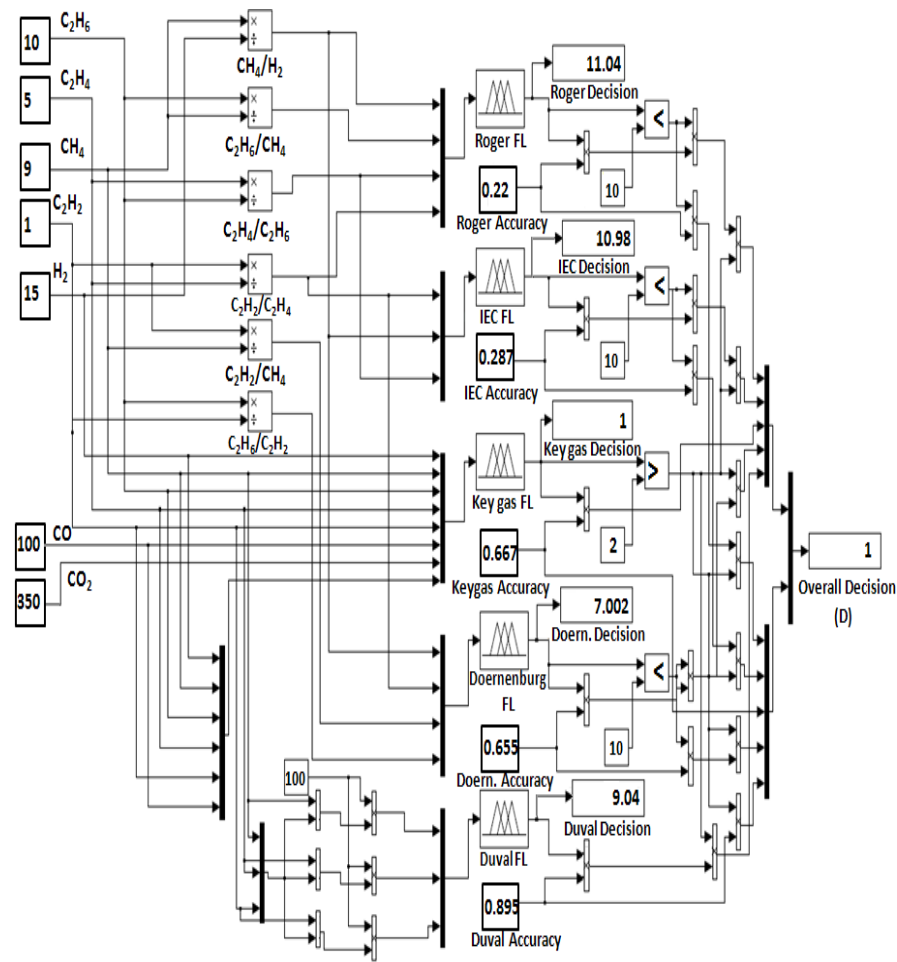

Figure 10. Proposed overall fuzzy logic model 
The inputs to the overall model are the concentration of the 7-key gases in particle per million and the output represents an overall decision $(D)$ on the DGA input data. The model is tested for the DGA data shown in Fig. 10, which shows that both Roger and IEC ratio methods provide a value greater than 10 that is corresponding to F6 (out of code) in Fig. 2 and hence, their contribution to the overall decision is eliminated. Fig. 10 also shows that, although Duval and Doerenburg methods result in a faulty condition, their contribution in the overall decision is also eliminated by the model as key gas method results in a normal condition and the overall decision in this case is only specified by the key gas method according to the flow chart shown in Fig. 9.

\section{VALIDATION OF THE PROPOSED MODEL}

To examine the accuracy of the proposed model, DGA results of 70 samples of pre known faults from previously published research papers [13, 18, 25-27] along with some collected DGA data are tested using the proposed model shown in Fig. 10 to compare the model's output with the actual fault. Three samples of each fault condition are shown

\begin{tabular}{|c|c|c|c|c|c|c|c|c|c|}
\hline$+\frac{\mathscr{E}}{0}$ & $\mathbf{W}$ & $\mathcal{E}$ & 蛋 & $\tilde{N}$ & $\widetilde{\Omega}$ & o & o & 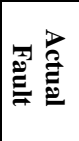 & 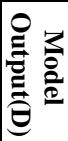 \\
\hline 1 & 2 & 7 & 0 & 0 & 0 & 0 & 132 & F5 & F5 \\
\hline 2 & 54 & 0 & 0 & 4 & 0 & 106 & 1303 & F5 & F5 \\
\hline 3 & 47 & 12 & 0 & 8 & 0 & 115 & 1113 & F5 & F5 \\
\hline 4 & 80 & 619 & 0 & 2480 & 326 & 268 & 2952 & $\mathrm{~F} 2$ & $\mathrm{~F} 2$ \\
\hline 5 & 231 & 3997 & 0 & 5584 & 1726 & 0 & 2194 & F2 & F2 \\
\hline 6 & 507 & 1053 & 17 & 1440 & 297 & 22 & 2562 & $\mathrm{~F} 2$ & $\mathrm{~F} 2$ \\
\hline 7 & 127 & 24 & 81 & 32 & 0 & 0 & 2024 & $\mathrm{~F} 4$ & $\mathrm{~F} 4$ \\
\hline 8 & 441 & 207 & 261 & 224 & 43 & 161 & 1123 & $\mathrm{~F} 4$ & $\mathrm{~F} 4$ \\
\hline 9 & 217 & 286 & 884 & 458 & 14 & 176 & 1544 & $\mathrm{~F} 4$ & $\mathrm{~F} 4$ \\
\hline 10 & 160 & 10 & 1 & 1 & 3 & - & - & F3 & F3 \\
\hline 11 & 240 & 20 & 96 & 28 & 5 & - & - & $\mathrm{F} 3$ & F3 \\
\hline 12 & 2587 & 7.88 & 0 & 1.4 & $\begin{array}{l}4.7 \\
\end{array}$ & - & - & $\mathrm{F} 3$ & F3 \\
\hline 13 & 23 & 6 & 31 & 23 & 172 & 225 & 2716 & F1 & F1 \\
\hline 14 & 103 & 74 & 0 & 9 & 80 & 754 & 2605 & F1 & F1 \\
\hline 15 & 124 & 166 & 0 & 59 & 87 & 530 & 3750 & F1 & F1 \\
\hline
\end{tabular}

in Table 5.

Table 5. Validation of the proposed approach

The first 9 samples in Table 5 are from [25] among which the first 3 samples show normal condition as all key gases along with the TDCG of the 3 samples are below the fault limit of key gas method. The model output in this case is 1 which is specified by the key gas method as the ratio methods lead to out-of-code result and Duval triangle cannot be used as it does not comprise any normal zone.

The actual fault of samples 4,5 and 6 is thermal fault that is not involving cellulose which is evidenced by the high amount of $\mathrm{C}_{2} \mathrm{H}_{4}$ and $\mathrm{CH}_{4}$. As reported in [25], oil sample number 4 was collected from a unit that has partly destroyed load tap changer contact while sample 5 was collected from a unit that has a defective core ground strap that exhibited signs of severe heating. Sample 6 was collected from a unit that suffers from burned low voltage coils. The model output agrees with the actual fault of these samples as it results in a value within the range of 4 to 6 which is corresponding to fault F2 in Table 1.
Samples 7, 8 and 9 indicate significant amount of $\mathrm{C}_{2} \mathrm{H}_{2}$ along with high concentration of other key gases. This indicates severe local overheating and arcing in these units which should be removed from service immediately for further inspections. According to [25], sample 7 was collected from a unit that has arcing between the tank and the high voltage lead which was reformed in another direction to solve the problem. The main reason of arcing fault in sample 8 was a severe arc to ground fault occurred during the shutdown procedure of the unit that was operating without its cooling system being turned on while sample 9 was collected from a unit suffering from a high voltage lead failure under oil [25]. The model output corresponding to these cases is a value between 8 and 10 which is equivalent to fault F4 in Table 1.

The concentration of $\mathrm{H}_{2}$ in samples 10,11 and 12 is considerably high to suggest a corona in oil. This agrees with the actual fault type reported in $[13,27]$ from which the three DGA results are taken. The fuzzy logic model provides a value in the range of 6 to 8 which is corresponding to fault F3 in Table 1.

The last three samples were collected from in-service transformers. The relatively high concentration of $\mathrm{CO}_{2}$ and $\mathrm{CO}$ along with other gases such as $\mathrm{C}_{2} \mathrm{H}_{6}$ in the samples indicates local overheating involving cellulose. The model output for these samples is a value between 4 and 6 which is corresponding to fault F2 in Table 1.

Table 6. Asset management decision based on model output

\begin{tabular}{|c|c|c|c|}
\hline Fault & $\begin{array}{c}\text { Model } \\
\text { output (D) }\end{array}$ & Fault diagnosis & $\begin{array}{l}\text { Recommended asset } \\
\text { management decision }\end{array}$ \\
\hline F5 & $0 \leq \mathrm{D}<2$ & No fault & $\begin{array}{l}\text {-Continue normal } \\
\text { operation }\end{array}$ \\
\hline F1 & $2 \leq \mathrm{D}<4$ & $\begin{array}{l}\text {-Cellulosic } \\
\text { decomposition } \\
\text {-Overheated cellulose }\end{array}$ & $\begin{array}{l}\text {-Exercise caution } \\
\text {-Furan analysis is } \\
\text { recommended } \\
\text {-Check generation rate } \\
\text { monthly }\end{array}$ \\
\hline $\mathrm{F} 2$ & $4 \leq \mathrm{D}<6$ & $\begin{array}{l}\text {-Oil decomposition } \\
\text {-Overheated oil }\end{array}$ & $\begin{array}{l}\text {-Exercise caution } \\
\text {-Check generation rate } \\
\text { weekly }\end{array}$ \\
\hline F3 & $6 \leq \mathrm{D}<8$ & $\begin{array}{l}\text {-Corona in oil } \\
\text { (low intensity electrical } \\
\text { discharge) }\end{array}$ & $\begin{array}{l}\text {-Exercise extreme } \\
\text { caution } \\
\text {-Check generation rate } \\
\text { weekly } \\
\text {-Plan outage }\end{array}$ \\
\hline F4 & $8 \leq \mathrm{D}<10$ & $\begin{array}{l}\text {-Arcing in oil } \\
\text { (high intensity electrical } \\
\text { discharge) }\end{array}$ & $\begin{array}{l}\text {-Exercise extreme } \\
\text { caution } \\
\text {-Check generation rate } \\
\text { daily }^{*} \\
\text { - Consider removal } \\
\text { from service }\end{array}$ \\
\hline
\end{tabular}

Manual collection of oil samples from suspected units is very risky. An online DGA detector is strongly recommended to avoid direct contact with suspected unit.

While the proposed model shows high agreement with the actual electrical faults (F3 and F4), it fails in some samples to distinguish thermal faults involving overheating in oil or cellulose (F1 and F2) and an engineering judgement should be used in this case.

Based on the model output, an asset management decision can be taken as proposed in Table 6 . 


\section{CONCLUSION}

This paper introduces a new interpretation approach for dissolved gas analysis (DGA) of transformer oil based on the integration of strength of all existing interpretation techniques into one powerful expert model. A comparative consistency and accuracy study using experimental results of 2000 transformer oil samples based on traditional DGA interpretation techniques is given. Results show that the current traditional methods are not consistent and they do not necessarily lead to the same conclusion for the same oil sample. Moreover, significant number of DGA results fall outside the proposed codes of ratio-based methods. All accuracy-weighted decisions of individual DGA interpretation techniques are combined together to provide one overall decision on DGA data. An asset management action based on the model output is also proposed. The agreement of the model output with actual faults within a transformer is tested against 70 DGA samples of pre-known fault type. While the model shows high agreement in identifying electrical faults, it fails in some samples to distinguish between the overheating in oil and cellulose. The proposed software should be used in conjunction with engineering judgment, operational circumstances and should be taken as a flag for asset management action. Also, comparison and analogies of sister transformers with similar operating conditions is recommended.

\section{REFERENCES}

[1] A. Abu-Siada and S. Islam, "A Novel On-Line Technique to detect Power Transformer Winding Faults", IEEE Transaction on Power Delivery, Vol. 27, No. 2, pp. 849-857, April 2012.

[2] M. Arshad and S. M. Islam, "Significance of cellulose power transformer condition assessment," IEEE Transactions on Dielectrics and Electrical Insulation, vol. 18, pp. 1591-1598, Oct 2011.

[3] M. Arshad, "Remnant Life Estimation Model Using Fuzzy Logic for Power Transformer Asset Management," PhD thesis, Curtin University of Technology, September 2005.

[4] Hydroelectric Research and Technical Services Group, "Facilities, Instructions, Standards and Techniques; Transformer Diagnostics," vol. 3-31, pp. 1-63, June 2003.

[5]X. Liu, F. Zhou, and F. Huang, "Research on on-line DGA using FTIR [power transformer insulation testing]," vol.3, pp. 1875-1880, 2002.

[6] Guide for Diagnostic Field Testing of Electric Power Apparatus - Part 1, "Oil-filled Power Transformers, Regulators, and Reactors," vol. IEEE 62$1995^{\text {TM }}, 1995$.

[7]"IEEE guide for the interpretation of gases generated in oil-immersed transformers," IEEE Std C57.104-2008 (Revision of IEEE Std C57.104-1991), pp. C1-27, 2009.

[8] "Mineral Oil-Impregnated Electrical Equipment" in Service-Interpretation of Dissolved and Free Gas Analysis, International Electrotechnical Commission (IEC) 60599, 1997.

[9]V. G. Arakelian, "Effective diagnostics for oil-filled equipment," IEEE Electrical Insulation Magazine, vol. 18, pp. 26-38, 2002.

[10]R. R. Rogers, "IEEE and IEC Codes to Interpret Incipient Faults in Transformers, Using Gas in Oil Analysis," IEEE Transactions on Electrical Insulation, vol. EI-13, pp. 349-354, 1978.

[11]M. Duval, "New techniques for dissolved gas-in-oil analysis," IEEE Electrical Insulation Magazine, vol. 19, pp. 6-15, 2003.

[12]N. A. Muhamad, B. T. Phung, and T. R. Blackburn, "Comparative study and analysis of DGA methods for mineral oil using fuzzy logic," International Power Engineering Conference, IPEC 2007, pp. 1301-1306, 2007.

[13]M. Hongzhong, L. Zheng, P. Ju, H. Jingdong, and Z. Limin, "Diagnosis of power transformer faults on fuzzy three-ratio method," the $7^{\text {th }}$ International Conference in Power Engineering, IPEC 2005, pp. 1-456, 2005.
[14] W. Zhenyuan, L. Yilu, and P. J. Griffin, "Neural net and expert system diagnose transformer faults," Computer Applications in Power, IEEE, vol. 13, pp. $50-55,2000$.

[15] S. Mofizul Islam, T. Wu, and G. Ledwich, "A novel fuzzy logic approach to transformer fault diagnosis," IEEE Transactions on Dielectrics and Electrical Insulation, vol. 7, pp. 177-186, 2000.

[16] A. Singh and P. Verma, "A review of intelligent diagnostic methods for condition assessment of insulation system in power transformers," International Conference on Condition Monitoring and Diagnosis, CMD 2008, pp. 1354-1357, 2008.

[17] A. Abu-Siada and S. Islam, "A new approach to identify power transformer criticality and asset management decision based on dissolved gasin-oil analysis," IEEE Transactions on Dielectrics and Electrical Insulation, vol. 19, pp. 1007-1012, June 2012.

[18] "IEEE Guide for the Interpretation of Gases Generated in Oil-Immersed Transformers," IEEE Std C57.104-1991, 1992.

[19] Hydroelectric Research and Technical Services Group, "Facilities, Illustrations, Standards and Techniques; Transformer Maintenance," US Department of Interior Bureau of Reclamation, Denver, Colorado, vol. 3-30, pp. 1-81, October 2000.

[20] A. Abu-Siada, Sin P. Lai, and S. M. Islam, "A Novel Fuzzy Logic Approach for Furan Estimation in Transformer Oil", IEEE Transaction on Power Delivery, Vol. 27, No. 2, pp. 469-474, April 2012.

[21]H. Li and M. Gupta, "Fuzzy Logic and Intelligent Systems," International Series in Intelligent Technologies, Kluwer Academic Publisher 1995.

[22] A. Abu-Siada, M. Arshad and S. Islam, "Fuzzy Logic Approach to Identify Transformer Criticality using Dissolved Gas Analysis", proceeding of the 2010 IEEE PES General Meeting, USA, July 2010.

[23] S. Hmood, A. Abu-Siada, M. Masoum and S. Islam," Standardization of DGA Interpretation Techniques using Fuzzy Logic Approach," proceeding of the IEEE International Conference on Condition Monitoring and Diagnosis conference, Bali, Indonesia, September 2012.

[24] K. Spurgeon, W. H. Tang, Q. H. Wu, Z. J. Richardson, and G. Moss, "Dissolved gas analysis using evidential reasoning," Science, Measurement and Technology, IEE Proceedings -, vol. 152, pp. 110-117, 2005.

[25] J. B. DiGiorgio, "Dissolved Gas Analysis of Mineral Oil Insulating Fluids," Northern Technology and Testing, pp. 1-21, 2005.

[26] Y. Fu and 1. Zhang, "Comprehensive method detecting the status of the transformer based on the artificial intelligence," International Conference on Power System Technology, PowerCon 2004, pp. 1638-1643, vol.2, 2004.

[27] D. V. S. Siva Sarma and G. N. S. Kalyani, "ANN approach for condition monitoring of power transformers using DGA," 2004 IEEE Region 10 Conference, TENCON 2004, pp. 444-447 Vol. 3, 2004.

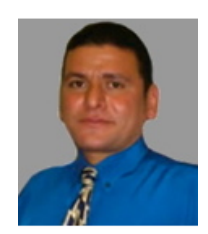

A. Abu-Siada (M'07, SM'12) received his B.Sc. and M.Sc. degrees from Ain Shams University, Egypt and the PhD degree from Curtin University, Australia, All in Electrical Engineering. Currently, he is a senior lecturer in the Department of Electrical and Computer Engineering at Curtin University. His research interests include power system stability, condition monitoring, power electronics and power quality. He is editor-in-chief for the electrical and electronic engineering international journal, a regular reviewer for many IEEE Transactions and a vice chair of the IEEE CIS, WA Chapter.

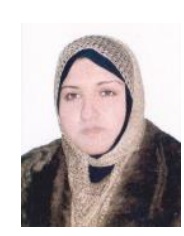

S. HMOOD received a B.Sc. degree in Electrical Engineering from Basrah University, Iraq. Currently, she is perusing a Masters of Philosophy study with the Department of Electrical and Computer Engineering at Curtin University, Australia. Her research interests include power transformer condition monitoring and application of artificial intelligence to power systems.

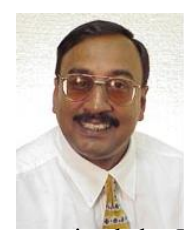

S. Islam (M'83, SM'93) received the B.Sc. from Bangladesh University of Engineering and Technology, Bangladesh, M.Sc. and $\mathrm{PhD}$ degrees from King Fahd University of Petroleum and Minerals, Saudi Arabia, all in electrical power engineering in 1979, 1983, and 1988 respectively. He is currently the Chair Professor in Electrical Power Engineering at Curtin University, Australia. He received the IEEE T Burke Haye's Faculty Recognition award in 2000. His research interests are in Condition Monitoring of Transformers, Wind Energy Conversion and Power Systems. He is regular reviewer for the IEEE Trans. on Energy Conversion, Power Systems and Power Delivery. Prof. Islam is an editor of the IEEE Transaction on Sustainable Energy. 